\title{
Vital Signs: Motor Vehicle Injury Prevention - United States and 19 Comparison Countries
}

Erin K. Sauber-Schatz, PhD ${ }^{1,2}$; David J. Ederer, $\mathrm{MPH}^{1}$; Ann M. Dellinger, $\mathrm{PhD}^{1}$; Grant T. Baldwin, $\mathrm{PhD}^{1}$

On July 6, 2016, this report was posted as an MMWR Early Release on the MMWR website (http://www.cdc.gov/mmwr).

\section{Abstract}

Background: Each year $>32,000$ deaths and 2 million nonfatal injuries occur on U.S. roads.

Methods: CDC analyzed 2000 and 2013 data compiled by the World Health Organization and the Organisation for Economic Co-operation and Development (OECD) to determine the number and rate of motor vehicle crash deaths in the United States and 19 other high-income OECD countries and analyzed estimated seat belt use and the percentage of deaths that involved alcohol-impaired driving or speeding, by country.

Results: In 2013, the United States motor vehicle crash death rate of 10.3 per 100,000 population had decreased 31\% from the rate in 2000; among the 19 comparison countries, the rate had declined an average of 56\% during this time. Among all 20 countries, the United States had the highest rate of crash deaths per 100,000 population (10.3); the highest rate of crash deaths per 10,000 registered vehicles (1.24), and the fifth highest rate of motor vehicle crash deaths per 100 million vehicle miles traveled (1.10). Among countries for which information on national seat belt use was available, the United States ranked 18th out of 20 for front seat use, and 13th out of 18 for rear seat use. Among 19 countries, the United States reported the second highest percentage of motor vehicle crash deaths involving alcohol-impaired driving (31\%), and among 15, had the eighth highest percentage of crash deaths that involved speeding (29\%).

Conclusions and Comments: Motor vehicle injuries are predictable and preventable. Lower death rates in other high-income countries, as well as a high prevalence of risk factors in the United States, suggest that the United States can make more progress in reducing crash deaths. With a projected increase in U.S. crash deaths in 2015, the time is right to reassess U.S. progress and set new goals. By implementing effective strategies, including those that increase seat belt use and reduce alcohol-impaired driving and speeding, the United States can prevent thousands of motor vehicle crashrelated injuries and deaths and hundreds of millions of dollars in direct medical costs every year.

\section{Introduction}

In the United States, reducing motor vehicle crash deaths has been reported as one of the great public health achievements of the 20th century (1). Despite this success, motor vehicle crashes remain a leading cause of death for Americans aged 1-54 years (2). Each year $>32,000$ deaths and 2 million nonfatal injuries occur on U.S. roads (2). The purposes of this study were to describe motor vehicle death data for the United States and 19 other high-income countries and to report seat belt use by seating location and the percentage of deaths that involved alcohol-impaired driving or speeding.

\section{Methods}

The number of country-specific motor vehicle crash deaths was provided by the World Health Organization's (WHO) most recent Global Status Report on Road Safety (3). Data representing $97.3 \%$ of the world's population were collected and validated by trained National Data Coordinators. To be included in the study, a country was required to have membership in the Organisation of Economic Co-operation and Development (OECD; http://www.oecd.org), meet the World Bank's definition for high income (gross national income per capita $\geq \$ 12,736$ ), have a population $>1$ million persons, and report the annual number of motor vehicle deaths and vehicle miles traveled. In addition, the difference between the country-reported motor vehicle crash death rate and the WHO-estimated rate could not exceed 1 death per 100,000 population. The United States and 19 of the 34 OECD member countries met these inclusion criteria, including 14 countries in Europe, two in Asia, two in the Americas, and two in Oceania.*

\footnotetext{
* Asia: Israel and Japan. Europe: Austria, Belgium, Denmark, Finland, France, Germany, Ireland, the Netherlands, Norway, Slovenia, Spain, Sweden, Switzerland, and the United Kingdom. The Americas: Canada and the
} United States Oceania: Australia and New Zealand. 
Data from 2000 and 2013 were used for analyses. Motor vehicle crash death rates were calculated per 100,000 population, per 100 million vehicle miles traveled, and per 10,000 registered vehicles. The percentages of crash deaths that involved alcohol-impaired driving and speeding were calculated. National data on seat belt use by seating location (front and rear) and country, were compared, when available.

Data on the number of deaths related to alcohol-impaired driving, reported seat belt use, and the number of registered vehicles were obtained from the Global Status Report on Road Safety (3). The U.S. estimates for seat belt use, based on observation of occupants in noncommercial vehicles at controlled intersections, and the number of deaths in 2013 were obtained from the National Highway Traffic Safety Administration $(4,5)$, and data for Canada were obtained from Transport Canada's National Collision Database (๑). Data on the number of vehicle miles traveled and deaths related to speeding were obtained from the International Road Traffic and Accident Database, ${ }^{\dagger}$ which is maintained by the International Transport Forum, an intergovernmental organization within the OECD (7). Original data presented in kilometers were converted to miles.

\section{Results}

All 20 countries reported the number of deaths and front seat belt use; 19 countries reported the percentage of deaths related to alcohol-impaired driving; 18 countries reported rear seat belt use; and 15 countries reported the percentage of deaths related to speeding. From 2000 to 2013, the U.S. motor vehicle death rate decreased $31 \%$, from 14.9 to 10.3 deaths per 100,000 population (Figure). The average death rate among all 19 comparison countries declined $56 \%$ between 2000 and 2013, from 10.0 deaths per 100,000 to 4.4 deaths per 100,000. Each of the 19 comparison countries had a higher percentage reduction in their motor vehicle crash death rate than did the United States, ranging from 38.3\% (Finland) to 75.1\% (Spain) (Figure).

During 2013, motor vehicle crash death rates from the 19 comparison countries ranged from 2.7 per 100,000 (Sweden) to 6.5 (Belgium) (Table 1) with mean and median rates of 4.4 and 4.1, respectively. The rate of motor vehicle crash deaths in the United States during 2013 (10.3 per 100,000 $[32,894$ deaths]) was approximately twice the average rate of the comparison countries. In the United States, these deaths represented 1.10 motor vehicle crash deaths per 100 million vehicle miles traveled; in the comparison countries, this rate ranged from 0.54 (Sweden) to 1.22 (Japan and Spain), with a mean of 0.85 and median of 0.80 (Table 1). Among all 20

\footnotetext{
$\dagger$ International Road Traffic and Accident Database. http://www.itf-oecd.org/ IRTAD.
}

countries, the rate in the United States (1.10) was the fifth highest, after Belgium (1.14), Slovenia (1.16), Japan (1.22) and Spain (1.22). The United States also had the highest rate of deaths per 10,000 registered vehicles (1.24); the rate in the comparison countries ranged from 0.44 (Finland) to 1.04 (Belgium), with a mean of 0.68 and median of 0.66 (Table 1 ). The United States had the second highest rate of registered vehicles per 1,000 population in 2013 (828). In the comparison countries, this rate per 1,000 population ranged from 369 (Israel) to 1,080 (Finland), with a mean and median of 670 (data not shown).

Alcohol-impaired driving was involved in $31 \%$ of U.S. motor vehicle crash deaths. Percentages of crash deaths that involved alcohol-impaired driving across 18 countries reporting these data ranged from 3.2\% (Israel) to $33.6 \%$ (Canada) $($ mean $=19.1 \%$; median $=18.0 \%)($ Table 2$)$. Speeding was involved in $29 \%$ of U.S. motor vehicle crash deaths. In 15 comparison countries reporting these data, the mean (28.8\%) and median (29.0\%) percentages were similar to the U.S., but ranged from 15\% (United Kingdom and Ireland) to $42 \%$ (Finland). The United States tied with New Zealand for the second highest percentage of motor vehicle crash deaths related to alcohol impairment, and had the eighth highest percentage of speeding involved deaths (Table 2).

During 2013, 87\% front seat belt use and 78\% rear seat belt use were reported nationally in the United States (Table 2). Among comparison countries, front seat belt use ranged from $86 \%$ (Austria) to $99 \%$ (France) with a mean of $94.1 \%$ and a median of $95.0 \%$. The United States ranked 18th out of 20 countries for front seat belt use. Among comparison countries, rear seat belt use ranged from 65\% (Austria) to 97\% (Germany) with a mean of $82.1 \%$ and a median of $84 \%$. The United States ranked 13 th in rear seat belt use among 18 countries reporting.

\section{Conclusions and Comments}

Although substantial progress has been made in reducing the number of motor vehicle crash deaths in the United States, motor vehicle crashes remain a serious public health problem resulting in $>32,000$ deaths and 2 million nonfatal injuries each year. Compared with 19 other high-income countries, the United States had the most motor vehicle crash deaths per 100,000 population and per 10,000 registered vehicles; the second highest percentage of deaths related to alcohol impairment; the third lowest national front seat belt use; and the lowest percentage decline in the rate of motor vehicle crash deaths between 2000 and 2013. If the United States had the same motor vehicle crash death rate as Belgium (the country with the second highest death rate), 12,000 fewer lives would have been lost in 2013 and an estimated $\$ 140$ million in direct 
FIGURE. Motor vehicle crash deaths per 100,000 population - 20 high-income countries, 2000 and 2013

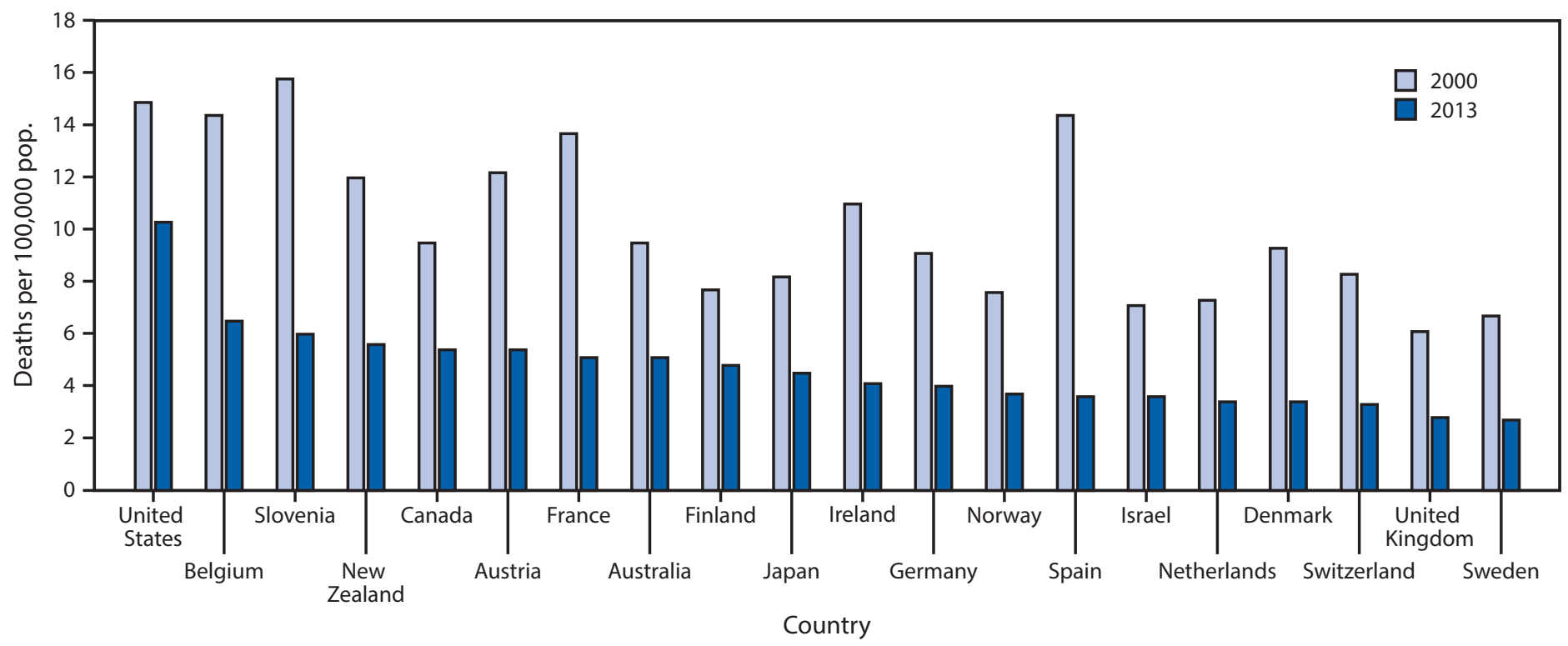

TABLE 1. Motor vehicle crash deaths per 100,000 population, per 100 million vehicle miles traveled, and per 10,000 registered vehicles, and percentage decreases from 2000 to 2013 — selected high-income countries, $2013^{*}$

\begin{tabular}{|c|c|c|c|c|c|c|c|c|}
\hline Country $^{\dagger}$ & $\begin{array}{l}\text { Reported no. } \\
\text { motor vehicle } \\
\text { crash deaths }\end{array}$ & $\begin{array}{l}\text { Motor vehicle } \\
\text { crash deaths } \\
\text { per } 100,000 \\
\text { population }\end{array}$ & $\begin{array}{l}\text { Decrease in } \\
\text { motor vehicle } \\
\text { crash deaths } \\
\text { per } 100,000 \\
\text { population } \\
2000-2013(\%)\end{array}$ & $\begin{array}{l}\text { Vehicle miles } \\
\text { traveled } \\
\text { (billions) }\end{array}$ & $\begin{array}{l}\text { Motor vehicle } \\
\text { crash deaths per } \\
100 \text { million } \\
\text { vehicle miles } \\
\text { traveled }\end{array}$ & $\begin{array}{c}\text { Decrease in } \\
\text { motor vehicle } \\
\text { crash deaths per } \\
100 \text { million } \\
\text { vehicle miles } \\
\text { traveled } \\
2000-2013(\%)\end{array}$ & $\begin{array}{l}\text { Total no. } \\
\text { registered } \\
\text { vehicles }\end{array}$ & $\begin{array}{c}\text { Motor vehicle } \\
\text { crash deaths } \\
\text { per } 10,000 \\
\text { registered } \\
\text { vehicles }\end{array}$ \\
\hline United States & 32,894 & 10.3 & 31.0 & $2,988.3$ & 1.10 & 28.0 & $265,043,362$ & 1.24 \\
\hline Belgium & 724 & 6.5 & 54.7 & 63.6 & 1.14 & 56.6 & $6,993,767$ & 1.04 \\
\hline Slovenia & 125 & 6.0 & 61.8 & 10.7 & 1.16 & 72.9 & $1,395,704$ & 0.90 \\
\hline New Zealand & 253 & 5.6 & 53.2 & 25.1 & 1.01 & 54.0 & $3,250,066$ & 0.78 \\
\hline Canada & 1,908 & 5.4 & 42.9 & 211.7 & 0.90 & 39.8 & $22,366,270$ & 0.85 \\
\hline Austria & 455 & 5.4 & 56.1 & 48.5 & 0.94 & 61.2 & $6,384,971$ & 0.71 \\
\hline France & 3,268 & 5.1 & 62.9 & 352.8 & 0.93 & 63.6 & $42,792,103$ & 0.76 \\
\hline Australia & 1,192 & 5.1 & 46.2 & 148.9 & 0.80 & 45.3 & $17,180,596$ & 0.69 \\
\hline Finland & 258 & 4.8 & 38.3 & 33.7 & 0.77 & 44.0 & $5,862,216$ & 0.44 \\
\hline Japan & 5,679 & 4.5 & 45.5 & 463.7 & 1.22 & 43.2 & $91,377,312$ & 0.62 \\
\hline Ireland & 188 & 4.1 & 63.1 & 29.8 & 0.63 & 66.0 & $2,482,557$ & 0.76 \\
\hline Germany & 3,339 & 4.0 & 55.6 & 450.9 & 0.74 & 59.3 & $52,391,000$ & 0.64 \\
\hline Norway & 187 & 3.7 & 51.2 & 27.3 & 0.69 & 59.4 & $3,671,885$ & 0.51 \\
\hline Spain & 1,680 & 3.6 & 75.1 & $137.7^{\S}$ & $1.22^{\S}$ & $68.4^{\S}$ & $32,616,105$ & 0.52 \\
\hline Israel & 277 & 3.6 & 49.5 & 31.8 & 0.87 & 56.4 & $2,850,513$ & 0.97 \\
\hline Netherlands & 570 & 3.4 & 53.4 & 79.1 & 0.72 & 55.2 & $9,612,273$ & 0.59 \\
\hline Denmark & 191 & 3.4 & 63.5 & 30.7 & 0.62 & 63.9 & $2,911,147$ & 0.66 \\
\hline Switzerland & 269 & 3.3 & 59.9 & 38.9 & 0.69 & 59.5 & $5,693,642$ & 0.47 \\
\hline United Kingdom & 1,770 & 2.8 & 54.0 & 316.0 & 0.56 & 53.0 & $35,582,650$ & 0.50 \\
\hline Sweden & 260 & 2.7 & 59.5 & 48.0 & 0.54 & 60.8 & $5,755,952$ & 0.45 \\
\hline Overall mean & $2,774.4$ & 4.7 & 53.9 & 276.9 & 0.86 & 55.5 & $30,810,704$ & 0.70 \\
\hline \multicolumn{9}{|c|}{ Comparison country statistics ( $n=19$; United States excluded) } \\
\hline Mean & $1,189.1$ & 4.4 & 55.1 & 134.2 & 0.85 & 57.0 & $18,482,670$ & 0.68 \\
\hline Median & 455.0 & 4.1 & 54.7 & 48.5 & 0.80 & 59.3 & $6,384,971$ & 0.66 \\
\hline Range & $125-5,679$ & $2.7-6.5$ & $38.3-75.1$ & $10.7-463.7$ & $0.54-1.22$ & $39.8-72.9$ & $\begin{array}{l}1,395,704- \\
91,377,312\end{array}$ & $0.44-1.04$ \\
\hline
\end{tabular}

* The number of deaths in 2013, total population, and the number of registered vehicles are from the Global Status Report on Road Safety 2015 . United States and Canada estimates for the number of deaths in 2013 were obtained from the National Highway Traffic Safety Administration and from Transport Canada's National Collision Database, respectively. The number of deaths in 2000, and vehicle miles travelled are from the Organisation for Economic Co-operation and Development/ International Transport Forum (OECD/ITF) Road Safety Annual Report 2015. Data were the most recently available data at the time the Global Status Report 2015 and the OECD/ITF Road Safety Annual Report 2015 were published.

+ Countries are listed in descending order by the number of deaths per 100,000 population.

$\S$ Vehicle miles traveled for Spain is for nonurban areas only. 
TABLE 2. Percentages of motor vehicle crash deaths, by alcohol impairment and speeding, and national seat belt use for front and rear seat occupants -20 selected high-income countries, 2013*

\begin{tabular}{|c|c|c|c|c|}
\hline \multirow[b]{2}{*}{ Country $^{\dagger}$} & \multicolumn{2}{|c|}{$\begin{array}{c}\text { Deaths with } \\
\text { specified risk factors } \\
(\%) \\
\end{array}$} & \multicolumn{2}{|c|}{$\begin{array}{c}\text { National } \\
\text { seat belt use } \\
(\%)\end{array}$} \\
\hline & $\begin{array}{l}\text { Alcohol- } \\
\text { impaired } \\
\text { driving }\end{array}$ & Speeding & $\begin{array}{c}\text { Front } \\
\text { seat }\end{array}$ & $\begin{array}{l}\text { Rear } \\
\text { seat }\end{array}$ \\
\hline United States & 31.0 & 29.0 & 87.0 & 78.0 \\
\hline Belgium & 25.0 & - & 86.4 & - \\
\hline Slovenia & 30.0 & 39.0 & 94.5 & 66.2 \\
\hline New Zealand & 31.0 & 33.0 & 96.0 & 90.0 \\
\hline Canada & 33.6 & 20.0 & 95.5 & 89.2 \\
\hline Austria & 6.8 & 28.0 & 86.0 & 65.0 \\
\hline France & 29.0 & 25.0 & 99.0 & 87.0 \\
\hline Australia & 30.0 & 33.0 & 97.0 & 96.0 \\
\hline Finland & 22.0 & 42.0 & 89.0 & 86.0 \\
\hline Japan & 6.2 & - & $97.9^{\S}$ & $68.2^{\S}$ \\
\hline Ireland & 15.6 & 15.0 & 94.0 & 89.0 \\
\hline Germany & 9.4 & 35.0 & 98.0 & 97.0 \\
\hline Norway & 17.0 & - & 94.0 & - \\
\hline Spain & 14.0 & 22.0 & 90.5 & 80.6 \\
\hline Israel & 3.2 & - & 95.0 & 74.0 \\
\hline Netherlands & 18.9 & 30.0 & 96.6 & 82.0 \\
\hline Denmark & - & 40.0 & $94.0^{\natural}$ & 81.0 \\
\hline Switzerland & 16.4 & 26.0 & 91.0 & 72.0 \\
\hline United Kingdom** & 16.0 & 15.0 & 95.0 & 88.0 \\
\hline Sweden & 19.0 & - & 98.0 & 84.0 \\
\hline Overall mean & 19.7 & 28.8 & 93.7 & 81.8 \\
\hline \multicolumn{5}{|c|}{ Comparison country statistics ( $n=19 ;$ United States excluded) } \\
\hline Mean & 19.1 & 28.8 & 94.1 & 82.1 \\
\hline Median & 18.0 & 29.0 & 95.0 & 84.0 \\
\hline Range & $3.2-33.6$ & $15.0-42.0$ & $86.0-99.0$ & $65.0-97.0$ \\
\hline
\end{tabular}

* Alcohol-impaired driving data are from the Global Status Report on Road Safety 2015. National seat belt estimates are also from the Global Status Report on Road Safety 2015, except for US data. United States estimates for seat belt use were reported from the National Highway Traffic Safety Administration 2013 data. Speeding estimates were reported in the Organisation for Economic Co-operation and Development/International Transport Forum (OECD/ITF) Road Safety Annual Report 2015. Data were the most recently available data at the time the Global Status Report 2015 and the OECD/ITF Road Safety Annual Report 2015 were published.

+ Countries are listed in descending order by the number of deaths per 100,000 population.

$\S$ Seatbelt use for Japan was reported for expressways only.

" Estimated seat belt use for Denmark was available for drivers of personal vehicles only; other front seat passengers are not included.

** The United Kingdom estimate was for Great Britain only. Great Britain makes up $97 \%$ of the population of the United Kingdom.

medical costs would have been averted. ${ }^{\S}$ Similarly, if the United States' motor vehicle crash death rate was equivalent to the average in the 19 comparison countries, at least 18,000 fewer lives would have been lost and an estimated $\$ 210$ million in direct medical costs would have been averted. ${ }^{\S}$ And, if the United States' motor vehicle crash death rate was equivalent to that in Sweden (the best performing country), at least 24,000 fewer lives would have been lost and an estimated \$281 million in direct medical costs would have been averted ${ }^{\S}$ in the United States in 2013.
When accounting for factors that differ across countries, including population size, vehicle miles traveled, and number of registered vehicles, the United States consistently ranked poorly among OECD comparison countries. This low ranking is consistent with other cross-national motor vehicle injury research findings $(8-10)$. Although it is difficult to identify and quantify the reasons for differences between the United States and the comparison countries, differences in policies and their enforcement, use of advanced engineering and technology, and differences in public acceptance and use of effective strategies have all contributed to reducing death rates in the best performing countries. The United States is highly dependent on transportation by personal vehicle. In 2014 , there were 1.2 vehicles per licensed driver and 2.1 vehicles per household in the United States, and the US share of world car registrations was 15.1\% (11). Given this reliance on personal vehicles, and need to address safety issues without delay, bringing policies in line with best practices (e.g., related to child passenger safety, seat belt use, and alcohol-impaired driving), enforcement, infrastructure, vehicles, and technologies such as ignition interlocks and automated enforcement (cameras) could help narrow the gap between the United States and higher performing countries $(3,12)$.

The complexity of improving road safety requires a broad view and more universal implementation and enforcement of existing effective strategies in the United States (12-14), as well as system-level changes in vehicle safety and transportation infrastructure (13). To maximize lives saved and injuries prevented in the United States, increasing restraint use and reducing alcohol-impaired driving could have the most, as well as an immediate, impact. Each year approximately half the passenger vehicle occupants who die in crashes in the United States are unrestrained ( $\mathrm{N}=9,777$ in 2013)(15). Implementing primary enforcement seat belt laws that cover occupants in all seating positions, and requiring the use of car seats and booster seats for motor vehicle passengers through at least age 8 years could increase restraint use and prevent injuries and deaths in the United States. During 2013, seat belts saved approximately 12,500 lives in the United States (15). If restraint use was at $100 \%$ in the United States, an additional 3,000 lives would be saved in a single year (15-17).

Each year in the United States, approximately 10,000 persons die in alcohol-impaired-driving crashes (18). Several proven prevention strategies could accelerate progress in the United States $(19,20)$, including publicized sobriety checkpoints (21), ignition interlocks (a breath-test device connected to a vehicle's ignition that prevents the vehicle from starting unless a blood alcohol concentration below a preset low limit is detected) for all convicted offenders (22), having lower blood

\$ https://wisqars.cdc.gov:8443/costT/. 
alcohol concentration limits, and maintaining and enforcing the minimum legal U.S. drinking age of 21 years (23).

In addition to effective interventions, there is an approach to road safety that began in Sweden and is gaining traction in the United States called Vision Zero (24). This is an aspirational vision that, in the long-term, seeks to eliminate death and serious injury on the road. Vision Zero starts with the premise that traffic injuries are not "accidents", no loss of life on the road is acceptable, all humans make mistakes, and traffic injuries are preventable. In the Vision Zero program, responsibility for crashes and injuries are shared between the users of the road, who are expected to follow basic rules, and the so-called "system providers," which include developers of road infrastructure, the automobile industry, and the police, who are responsible for the functioning of the system. Eighteen U.S. cities have adopted this approach and many more are considering implementing it. Additionally, several U.S. states and the Federal Highway Administration have embraced "Towards Zero Deaths," which is based on the Vision Zero philosophy.9

The findings in this report are subject to at least three limitations. First, definitions and reporting of motor vehicle deaths vary by country. To limit these differences, countries with motor vehicle death rates that differed substantially from WHO's estimated rates were excluded from the analysis. Second, legal definitions and reporting of alcohol-impaired driving, speeding, and seat belt use also vary among countries. For example, in the United States, the United Kingdom, and Canada, drivers are considered to be alcohol impaired when their blood alcohol concentration is $\geq 0.08$ grams per deciliter $(\mathrm{g} / \mathrm{dL})$; whereas, in the other comparison countries, drivers have lower blood alcohol concentrations limits $(0.02-0.05 \mathrm{~g} / \mathrm{dL})$. Also, in Canada, all provinces except Quebec have administrative laws penalizing drivers (e.g., 3-day license suspension, fine, or 3-day vehicle impoundment) with blood alcohol concentrations of $0.05-0.08 \mathrm{~g} / \mathrm{dL}$ (0.04-0.08 in Saskatchewan) (25). Finally, the United States is larger and more populous than the comparison countries and has a lower population density (rural roads have higher death rates) than most. Travel behaviors, transportation modes, and infrastructure also vary widely among countries. These differences might account for some of the differences in motor vehicle death rates; however, by reporting rates per 100,000 population, per 100 million miles traveled, and per 10,000 registered vehicles, it was possible to partially adjust for these differences.

Motor vehicle injuries are predictable and preventable, and yet, in 2013, 90 persons died every day on U.S. roads. Lower rates in other high-income countries, as well as a high prevalence of risk factors in the United States, suggest that the United States can

\section{Key Points}

- In 2013, the United States motor vehicle crash death rate of 10.3 per 100,000 population had decreased $31 \%$ from the rate in 2000; the average rate among 19 high income comparison countries had declined $56 \%$ during this time, nearly twice as much. The United States had the lowest percentage decline among the comparison countries from 2000 to 2013.

- Motor vehicle crash deaths are responsible for $>32,000$ deaths and 2 million nonfatal injuries per year.

- Compared with 19 other high-income countries, the United States had the most motor vehicle crash deaths per 100,000 population and per 10,000 registered vehicles; second highest percentage of deaths involving alcohol-impaired driving; and third lowest national front seat belt use.

- Despite proven measures in motor vehicle injury prevention, in 2013, 90 persons died every day on U.S. roads. Lower rates in other high-income countries suggest that the United States can make more progress in reducing motor vehicle crash deaths.

- If the United States' motor vehicle crash death rate was equivalent to the rate in Belgium (the country with the second highest death rate), 12,000 fewer lives would have been lost and $\$ 140$ million in direct medical costs would have been averted in 2013 .

- If the United States' motor vehicle crash death rate was equivalent to the average of the 19 comparison countries, at least 18,000 fewer lives would have been lost and $\$ 210$ million in direct medical costs would have been averted in 2013 .

- If the United States' motor vehicle crash death rate was equivalent to the rate in Sweden (the best performing country), at least 24,000 fewer lives would have been lost and $\$ 281$ million in direct medical costs would have been averted in 2013 .

- Additional information is available at http://www.cdc. gov/vitalsigns.

make more progress toward reducing motor vehicle crash deaths. With a projected increase in U.S. crash deaths in 2015 (26), the time is right to reassess progress and set new goals. By implementing proven effective strategies, the United States can save thousands of persons and hundreds of millions of dollars in direct medical costs from motor vehicle crash injuries and deaths every year.

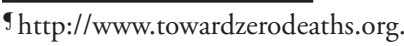




\section{Acknowledgment}

David Sleet, PhD, FAAHB, National Center for Injury Prevention and Control, CDC.

\footnotetext{
${ }^{1}$ Division of Unintentional Injury Prevention, National Center for Injury Prevention and Control, CDC; ${ }^{2}$ United States Public Health Service.

Corresponding author: Erin K. Sauber-Schatz, esauberschatz@cdc.gov, 770-488-0566.
}

\section{References}

1. CDC. Motor-vehicle safety: a 20th century public health achievement. MMWR Morb Mortal Wkly Rep 1999;48:369-74.

2. CDC. WISQARS (Web-Based Injury Statistics Query and Reporting System). Atlanta, GA: US Department of Health and Human Services, CDC; 2014. http://www.cdc.gov/injury/wisqars

3. World Health Organization. Global status report on road safety 2015. Geneva, Switzerland: World Health Organization Press; 2015. http:// www.who.int/violence_injury_prevention/road_safety_status/2015/en/

4. National Highway Traffic Safety Administration. FARS (Fatality Analysis Reporting System). Washington, DC: US Department of Transportation; 2016. http://www-fars.nhtsa.dot.gov/Main/index.aspx

5. Pickrell TM, Liu C. Occupant restraint use in 2013: results from the NOPUS controlled intersection study. Washington, DC: National Highway Traffic Safety Administration; 2015. https://crashstats.nhtsa. dot.gov/Api/Public/ViewPublication/812080

6. Transport Canada. National collision database. Ottawa, ON: Transport Canada; 2015. http://wwwapps2.tc.gc.ca/Saf-Sec-Sur/7/NCDBBNDC/p.aspx?l=en

7. Organisation for Economic Co-operation and Development/ International Transport Forum. Road safety annual report 2015. Paris, France: Organisation for Economic Co-operation and Development; 2015. http://www.itf-oecd.org/sites/default/files/ docs/15irtadannualreport_0.pdf

8. Fenelon A, Chen LH, Baker SP. Major causes of injury death and the life expectancy gap between the United States and other high-income countries. JAMA 2016;315:609-11. http://dx.doi.org/10.1001/jama.2015.15564

9. Luoma J, Sivak M. Why is road safety in the US not on par with Sweden, the UK, and the Netherlands? Lessons to be learned. European Transport Research Review 2014;6:295-302. http://dx.doi.org/10.1007/ s12544-014-0131-7

10. Ahangari H, Atkinson-Palombo C, Garrick NW. Progress towards zero, an international comparison: Improvements in traffic fatality from 1990 to 2010 for different age groups in the USA and 15 of its peers. J Safety Res 2016;57:61-70. http://dx.doi.org/10.1016/j.jsr.2016.03.006

11. Davis SC, Diegel SW, Boundy RG. Transportation energy data book. 34th ed. Oak Ridge, TN: Oak Ridge National Laboratory; 2015. http:// cta.ornl.gov/data/index.shtml

12. CDC. Prevention status reports: national summary. Atlanta, GA: US Department of Health and Human Services, CDC; 2016. http://www. cdc.gov/psr/national-summary.html

13. Goodwin A, Thomas L, Kirley B, Hall W, O’Brien N, Hill K. Countermeasures that work: a highway safety countermeasure guide for state highway safety offices. 8th ed. Washington, DC: National Highway Traffic Safety Administration; 2015. http://www.ghsa.org/ html/publications/countermeasures.html
14. CDC. Motor vehicle prioritizing interventions and cost calculator for states (MV PICCS) 2.0. Atlanta, GA: US Department of Health and Human Services, CDC; 2015. http://www.cdc.gov/motorvehiclesafety/calculator/

15. National Highway Traffic Safety Administration; National Center for Statistics and Analysis. Occupant protection: 2013 data. Washington, DC: US Department of Transportation; 2015. https://crashstats.nhtsa. dot.gov/Api/Public/ViewPublication/812153

16. Dinh-Zarr TB, Sleet DA, Shults RA, et al.; Task Force on Community Preventive Services. Reviews of evidence regarding interventions to increase the use of safety belts. Am J Prev Med 2001;21(Suppl):48-65. http://dx.doi.org/10.1016/S0749-3797(01)00378-6

17. CDC. Buckle up: restraint use state fact sheets. Atlanta, GA: US Department of Health and Human Services, CDC; 2016. http://www. cdc.gov/motorvehiclesafety/seatbelts/states.html

18. National Center for Statistics and Analysis. Alcohol-impaired driving: 2014 data. Washington, DC: National Highway Traffic Safety Administration; 2016. https://crashstats.nhtsa.dot.gov/Api/Public/ ViewPublication/812231

19. Guide to Community Preventive Services. Motor vehicle-related injury prevention: reducing alcohol-impaired driving. Atlanta, GA: US Department of Health and Human Services, CDC; 2014. www. thecommunityguide.org/mvoi/AID/index.html

20. CDC. Sobering facts: drunk driving state fact sheets. Atlanta, GA: US Department of Health and Human Services, CDC; 2016. http://www. cdc.gov/motorvehiclesafety/impaired_driving/states.html

21. Bergen G, Pitan A, Qu S, et al.; Community Preventive Services Task Force. Publicized sobriety checkpoint programs: a community guide systematic review. Am J Prev Med 2014;46:529-39. http://dx.doi. org/10.1016/j.amepre.2014.01.018

22. Elder RW, Voas R, Beirness D, et al.; Task Force on Community Preventive Services. Effectiveness of ignition interlocks for preventing alcohol-impaired driving and alcohol-related crashes: a Community Guide systematic review. Am J Prev Med 2011;40:362-76. http://dx.doi. org/10.1016/j.amepre.2010.11.012

23. Task Force on Community Preventive Services. Recommendations to reduce injuries to motor vehicle occupants: increasing child safety seat use, increasing safety belt use, and reducing alcohol-impaired driving. Am J Prev Med 2001;21(Suppl):16-22. http://dx.doi.org/10.1016/ S0749-3797(01)00380-4

24. Tingvall C, Haworth N. Vision zero: an ethical approach to safety and mobility. In: Jraiw K, ed. Proceedings of the 6th institute of transport engineers international conference on road safety and traffic enforcement: beyond 2000; Sept 6-7, 1999; Melbourne, Australia.

25. Fell JC. The merits of adopting a 0.05 administrative blood alcohol concentration limit for driving. Am J Public Health 2016;106:977-8.

26. National Center for Statistics and Analysis. Early estimate of motor vehicle traffic fatalities in 2015. Washington, DC: National Highway Traffic Safety Administration; 2016. https://crashstats.nhtsa.dot.gov/ Api/Public/ViewPublication/812269 